\title{
Vibration welding of alpha and beta isotactic polypropylenes: Mechanical properties and structure
}

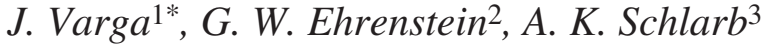 \\ ${ }^{1}$ Laboratory of Plastics and Rubber Technology, Department of Physical Chemistry and Material Science, Budapest \\ University of Technology and Economics, H-1111 Budapest, Múegyetem rkp. 3, Hungary \\ ${ }^{2}$ Lehrstuhl für Kunststofftechnik, University of Erlangen-Nürnberg, D-91058 Erlangen-Tennelohe, Am Weichselgarten 9 , \\ Germany \\ ${ }^{3}$ Institut für Verbundwerkstoffe GmbH, Universität Kaiserslautern, D-67663 Kaiserslautern, Erwin-Schrödinger Str., \\ Germany
}

Received 4 January 2008; accepted in revised form 12 January 2008

\begin{abstract}
Propylene homo- and copolymers (both random and block types) with and without beta nucleation were injection moulded and the related plaques joined by linear vibration welding. The melt flow index (MFI) of the polypropylenes was different. During vibration welding the pressure has been varied $(0.5,2$ and $8 \mathrm{MPa})$. The properties of the welded plaques were determined under both static (tensile) and dynamic conditions (Charpy impact). It was found that the mechanical performance of the welds could strongly be improved when beta nucleated PP plaques were combined with each other. In other combinations the 'weaker' alpha modification controls the mechanical response. The supermolecular structure of the weld was assessed by polarised light microscopy using thin microtomed sections. Formations of the weld morphology along with its effects on the mechanical performance were discussed.
\end{abstract}

Keywords: processing technologies, isotactic polypropylene, vibration welding, mechanical properties, morphology

\section{Introduction}

Welding is widely used to produce plastic products of complicated shape and large size [1]. The structure-property relationships of vibration welded semicrystalline polymers, especially in case of isotactic polypropylene (iPP), have been studied comprehensively [2-9]. It was established that the morphology of the weld joint (seam) reflects very sensitively the conditions of the welding process (e.g. [3-8]). During vibration welding the parts to be welded are clamped in tools and pressed together with a defined load $(F)$. After this 'closeup' process, the upper part is brought to oscillation (vibration step) - cf. Figure 1. Depending on the type of the oscillation movement one distinguishes

${ }^{*}$ Corresponding author, e-mail: jvarga@ mail.bme.hu

(C) BME-PT and GTE

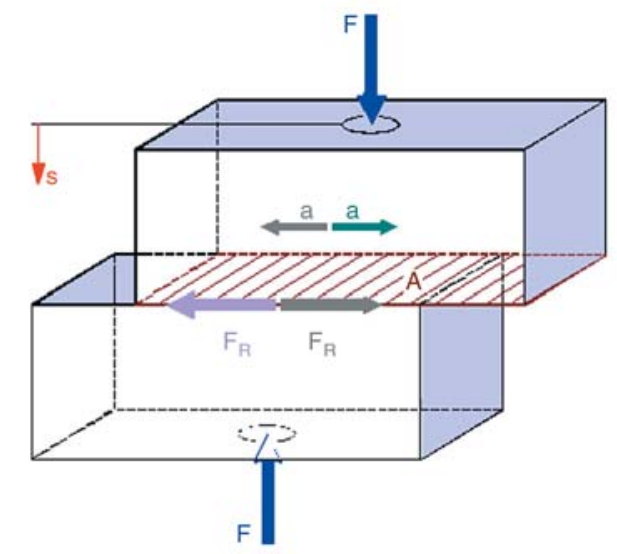

Figure 1. Scheme of the linear vibration welding. Note: this figure also indicates the major technological parameters: $F$ - load, $A$ - initial surface of the parts, $a$ - amplitude, $s$ - penetration 
between linear, rotation and twisting types vibration welding [9]. The surface layers of the thermoplastic parts became molten owing to the frictional heat evolved during welding. As a consequence, a molten layer appears between the welded parts. Under pressure, some molten polymer flows outside of the welding surface creating some flash when the parts move against each other. The relative movement of the weldable parts is termed as welding distance $(s)$ or penetration.

Depending on the technological parameters, viscoelasticity of the polymer melt and the thermal conductivity conditions, the heat development and loss (via heat radiation and conduction, incl. the heat capacity of the flash giving melt) may be equilibrated. This results in quasi-stationary melt stage in the weld. Recall that heat generates due to the periodic loading of the melt of viscoelastic nature (mechanical loss work) in the quasi-stationary stage. Next the vibration is stopped but the parts are still held together under pressure. In this pressure holding phase the welding joint solidifies owing to cooling, which is accompanied by crystallization from the melt. Major technology parameters of linear vibration welding are: welding pressure ( $p$, which is calculated by dividing the closing force, $F$, by the initial contact surface of the parts), vibration time $\left(t_{v}\right)$, amplitude and frequency of the vibration ( $a$ and $f$, respectively). Note that the above parameters control the thermal and flow behaviours of the molten zone in the welding joint. The welding process was split in four phases by Potente et al. [2]: 1 - friction in the solid phase, 2 onset of an instationary melt, 3 - appearance of a quasi-stationary melt, and 4 - cooling. These four phases are displayed in Figure 2, which shows the

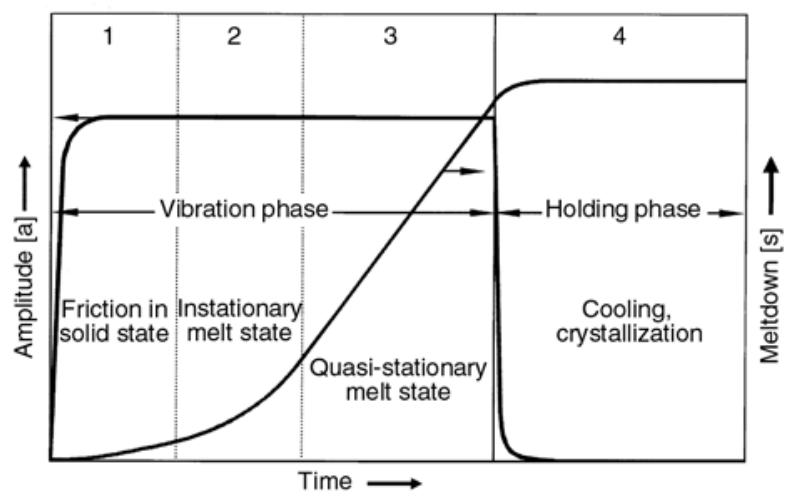

Figure 2. Phases of the vibration welding showing also the changes in the amplitude $(a)$ and welding distance or penetration $(s)$ in time variation of the penetration $(s)$ and vibration amplitude $(a)$ as a function of the welding time. By increasing the welding pressure the related curves shift towards smaller times. Parallel to the increase in the welding pressure, the thickness and strength of the weld joint decrease monotonously [9].

iPP is a polymer existing in several crystalline modifications (polymorphism) [10]. Adding selective beta nucleators, the formation of the beta modification of iPP can be triggered, even under usual processing conditions $[10,11]$. Beta-iPP has a higher toughness than the alpha version, which form usually in non-nucleated iPP. The toughness improvement is more prominent for high than for low molecular weight iPP grades $[10,12]$. Therefore, it is of great importance to check whether or not the high toughness of beta iPP can be exploited in welded parts. So, the present contribution is dedicated to the vibration welding of beta-nucleated injection moulded iPP plaques. In order to get more general information, the work covered the following combinations of the welded plaques: alpha/ alpha (i.e. non-nucleated/non-nucleated), alpha/ beta (i.e. non-nucleated/beta-nucleated) and beta/ beta (beta-nucleated/beta-nucleated). The morphology of the weld joints was studied by polarised light microscopy (PLM) and discussed.

\section{Experimental}

\subsection{Production and characterisation of the plaques to be welded}

Plaques $(145 \times 70 \times 4 \mathrm{~mm})$ were injection moulded on an Engel ES 200/50HZ machine. The injection molding parameters were: melt temperature: $240^{\circ} \mathrm{C}$, injection speed: $70 \mathrm{~mm} / \mathrm{s}$, holding pressure: $330 \mathrm{MPa}$. As propylene homopolymers the following Tipplen grades of Tisza Chemical Works (Tiszaújváros, Hungary) were selected: Tipplen H384, Tipplen H543 and Tipplen H781. In addition to of homopolymers, also propylene-co-ethylene copolymers - both random (Tipplen R351) and block (Tipplen K392) types - were involved in this study. The iPP types were modified by incorporation of crystal water free calcium salt of pimelic acid in $0.1 \mathrm{wt} \%$. This highly selective proprietary beta-nucleating agent was developed in our laboratory [13]. For the various iPPs the following coding was introduced: the first capital refers to the absence or presence of the beta nucleator (A and B, 
respectively). The second capital indicates the type of the PP, so the homopolymer, random and block copolymers are given by $\mathrm{H}, \mathrm{R}$ and $\mathrm{K}$, respectively. Finally, the third number refers to the melt flow index (MFI) of the related PP grade. Note that with increasing number the MFI of the PP decreases. All above iPPs crystallise predominantly in the beta form in the presence the above-disclosed nucleator, at least when plaques are produced by compression molding, whereby a long isothermal step of the crystallisation $\left(T_{c}=110-135^{\circ} \mathrm{C}\right)$ was set [10]. On the other hand, the injection-moulded plaques possess a molding-induced skin-core structure with mixed polymorphic composition [11]. This affects markedly the mechanical performance of the related systems [14]. The core of a beta-nucleated iPP contains beta-spherulites and the skin layer consists of alpha-cylindrites, as demonstrated in our previous works [11]. The morphology and polymorphic composition in the skin layer depend on the iPP type (homo- or copolymer) and its characteristics (mostly MFI), distance from the gate and injection speed. The beta content of the core of the plaques was assessed by the $k$-value, which was introduced by Turner Jones et al. [15]. The $k$-values were determined by wide angle $\mathrm{X}$-ray scattering (WAXS) after removal of the skin layers by polishing. The $k$-values of the injection-moulded beta plaques, along with the skin layer thicknesses are reported in Table 1. Table 1 also lists the measured MFI values. Recall that information on the MFI contains the last number in our coding. Attention should be paid to the fact that the same number refers to very similar MFI values for all kind of iPPs. This is in accord with the designation policy of the iPP producer.

\subsection{Welding}

Welding tests were run on a fully automatic Branson Ultraschall device Model 2800. During weld- ing the penetration and pressure can be monitored as a function of time. The welding pressure was varied $(8,2$ and $0.5 \mathrm{MPa})$ while the amplitude $(0.7 \mathrm{~mm})$ and frequency $(240 \mathrm{~Hz})$ of the vibration were kept constant. As various iPP pairs were used for welding, the above-introduced code had to be extended as follows: $\mathrm{AA}, \mathrm{AB}$ and $\mathrm{BB}$ mean the welding pairs alpha/alpha, alpha/beta and beta/beta, respectively. In the new code this capital combination appears first.

\subsection{Mechanical testing}

The tensile strength (sigma) of the parent and welded plaques was determined by a Zwick universal testing machine (Ulm, Germany) at ambient temperature $(R T)$ with $20 \mathrm{~mm} / \mathrm{min}$ deformation rate. The Charpy impact strength (more precisely: energy, $W$ ) was measured by an impact pendulum at the following conditions: $R T$, incident impact speed: $2.9 \mathrm{~m} / \mathrm{s}$, incident energy of the hammer: $2 \mathrm{~J}$. Prior to the related tests the flash of the welded joints was removed. Specimens cut from the parent plaques did not break under these impact conditions. Therefore they were notched until a depth of ca. $1.5 \mathrm{~mm}$ (i.e. $1 / 3$ of the overall thickness in line with the related standard).

\subsection{Morphology detection}

The morphology of the injection moulded plaques and the welds was studied in PLM using microtomed sections (ca. $10 \mu \mathrm{m}$ thickness). The microsections were embedded in a thermoset resin (Eukitt) and cured. Inserting a lambda-plate in between the polariser and analyser diagonally assessed the type of birefringence. PLM micrographs taken with and without using lambda plate are presented in this paper.

Table 1. Characteristics of the PP types and their injection molded plaques used

\begin{tabular}{|c|c|c|c|c|}
\hline \multirow{2}{*}{ Sample } & \multirow{2}{*}{$\begin{array}{c}\text { MFI* } \\
{[\mathbf{d g} / \mathbf{m i n}]}\end{array}$} & Non-nucleated & \multicolumn{2}{|c|}{$\boldsymbol{\beta}$-nucleated } \\
\cline { 3 - 5 } & 13.4 & Thickness of skin $(\mathbf{d}),[\boldsymbol{\mu} \mathbf{m}]$ & Thickness of skin $(\mathbf{d}),[\boldsymbol{\mu} \mathbf{m}]$ & k value \\
\hline H3 & $<0$ & $<20$ & 0.89 \\
\hline H5 & 5.5 & $\sim 40$ & $\sim 40$ & 0.89 \\
\hline H7 & 0.76 & $\sim 400$ & $<400$ & 0.90 \\
\hline R3 & 11 & $<20$ & $<20$ & 0.85 \\
\hline K3 & 12 & $<20$ & $<20$ & 0.99 \\
\hline
\end{tabular}

*MFI was measured at $230^{\circ} \mathrm{C}$ with $21.6 \mathrm{~N}$ load 


\section{Results and discussion}

\subsection{Mechanical properties}

The tensile mechanical characteristics of the welded PP pairs as functions of their types and welding pressure are summarised in Table 2. One can see that the best mechanical performance exhibited those weld pairs, which were produced at the lowest welding pressure. The tensile strengthstrain curves of the related specimens were similar to those of semicrystalline polymers showing prominent necking and substantial deformation (several hundred \%) before final fracture. The high elongation (ductility) was due to the sharp necking, which occurred away of the weld joint, i.e. in one or other half ('leg') of the welded specimens (cf. Figure 3). The iPP pairs welded at low welding pressure did not break at the weld line. So, the yielding stress of the parent plaques agreed fairly well with that of the welded ones. Note that alphaiPP undergoes a highly localised necking, whereas this is far more diffuse in the beta-modification. In welded pairs, containing beta-PP, necking appears

Table 2. Tensile strength $(\sigma)$ of the PP pairs welded at different pressures (viz. 0.5, 2 and $8 \mathrm{MPa}$ )*

\begin{tabular}{|c|c|c|c|}
\hline Sample & $\begin{array}{c}\sigma(8) \\
{[\mathrm{MPa}]}\end{array}$ & $\begin{array}{c}\sigma(2) \\
{[\mathrm{MPa}]}\end{array}$ & $\begin{array}{l}\sigma(0,5) \\
{[\mathrm{MPa}]}\end{array}$ \\
\hline A-H3 & \multicolumn{3}{|c|}{35.1} \\
\hline B-H3 & \multicolumn{3}{|c|}{28.4} \\
\hline AA-H3 & 26.5 & 30.2 & 32.9 \\
\hline BB-H3 & 24.9 & 26.8 & $>29.0$ \\
\hline AB-H3 & 24.6 & 26.5 & $>29.8$ \\
\hline A-H5 & \multicolumn{3}{|c|}{34.3} \\
\hline B-H5 & \multicolumn{3}{|c|}{27.4} \\
\hline AA-H5 & 25.7 & 31.6 & 32.7 \\
\hline BB-H5 & 24.8 & 26.8 & $>27.4$ \\
\hline AB-H5 & 23.9 & 26.5 & $>28.0$ \\
\hline A-H7 & \multicolumn{3}{|c|}{30.8} \\
\hline B-H7 & \multicolumn{3}{|c|}{26.5} \\
\hline AA-H7 & 13.1 & 18.1 & $>30.2$ \\
\hline BB-H7 & 21.1 & 24.3 & $>26.1$ \\
\hline AB-H7 & 20.5 & 23.8 & $>26.6$ \\
\hline A-R3 & \multicolumn{3}{|c|}{28.7} \\
\hline B-R3 & \multicolumn{3}{|c|}{25.8} \\
\hline AA-R3 & 25.6 & 26.8 & 27.5 \\
\hline BB-R3 & 21.8 & 23.3 & $>24.5$ \\
\hline AB-R3 & 23.0 & 25.0 & 25.5 \\
\hline A-K3 & \multicolumn{3}{|c|}{23.8} \\
\hline B-K3 & \multicolumn{3}{|c|}{19.2} \\
\hline AA-K3 & 15.1 & 17.0 & 21.0 \\
\hline BB-K3 & 15.3 & 16.2 & $>19.2$ \\
\hline $\mathrm{AB}-\mathrm{K} 3$ & 15.2 & 16.0 & 19.5 \\
\hline
\end{tabular}

*The tensile strength was determined at RT using $20 \mathrm{~mm} / \mathrm{min}$ deformation speed. The coding is referred in the text

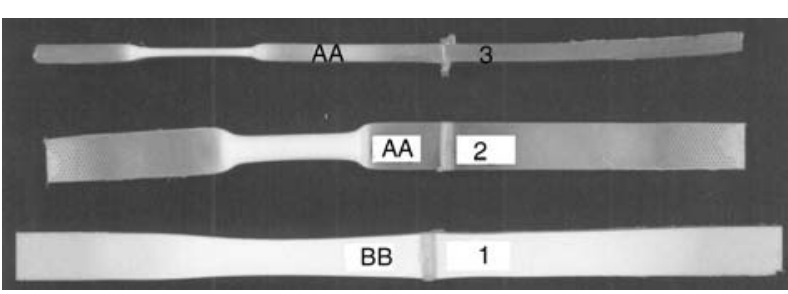

Figure 3. Necking due to static mechanical loading in the dumbbells cut from the welded pairs AA-H7 and BB-H7. Designation: 1 - BB-H7: flat on, 2 - AA-H7 flat on, 3 - AA-H7 edge on

exclusively in the beta PP section (cf. Figure 3). This can be attributed to the difference in the yield stresses between beta and alpha-iPPs - beta-iPP yields always at a lower stress than the alpha version [10]. Specimens welded at high pressures (2 and $8 \mathrm{MPa}$ ) had low tensile strength data and they break in the weld. This was accompanied with low elongation at break (several percent) values, as well.

\subsection{Impact strength of the welds}

Results of the Charpy impact tests are summarised in Table 3. This table also contains the notched Charpy impact strength data (marked by asterisk) of the parent injection moulded plaques. However, the latter data are of indicative nature and serve merely to collate the impact performance of the various PPs used. Considering the notched Charpy impact strengths of the parent plaques, one can recognise that the toughness increases with decreasing MFI for both alpha- and beta-iPPs according to the expectation. The relative increment in the Charpy impact strength is higher for the beta-nucleated compared to the corresponding alpha versions. Comparing the impact strength of the $\mathrm{H}, \mathrm{R}$ and $\mathrm{K}$ grades at the same MFI (which is rather high in this case), one can only notice a slight increase in the toughness owing to beta nucleation. This is in line with the state of knowledge as disclosed for example in [10,11].

Data in Table 3 display that the Charpy impact strength of the welded plaques increases markedly with decreasing MFI for both alpha- and beta-iPPs. The welded plaques from $\mathrm{H} 7 \mathrm{iPP}$ possess the highest impact toughness. For example, BB-H7, when welded at low pressure, exhibits outstanding impact strength (ca. $70 \mathrm{~kJ} / \mathrm{m}^{2}$ ). It is noteworthy that both tensile and impact strengths of the $\mathrm{AA}$ and $\mathrm{AB}$ 
welded pairs are practically the same (cf. data in Tables 2 and 3). This suggests that the 'weak site' is in the non-nucleated (alpha) section. In fact, the

Table 3. Notched and unnotched Charpy impact strength (precisely: energy) data for the PP pairs welded at different pressures (viz. 0.5, 2 and $8 \mathrm{MPa}$ )

\begin{tabular}{|c|c|c|c|}
\hline Sample & $\begin{array}{c}\mathbf{W}(\mathbf{8}) \\
{\left[\mathrm{kJ} / \mathrm{m}^{2}\right]}\end{array}$ & $\begin{array}{c}\mathrm{W}(\mathbf{2}) \\
{\left[\mathrm{kJ} / \mathrm{m}^{2}\right]}\end{array}$ & $\begin{array}{c}\mathrm{W}(\mathbf{0 , 5}) \\
{\left[\mathrm{kJ} / \mathrm{m}^{2}\right]}\end{array}$ \\
\hline A-H3 & \multicolumn{3}{|c|}{$3.53^{*}$} \\
\hline B-H3 & \multicolumn{3}{|c|}{$4.41^{*}$} \\
\hline AA-H3 & 5.00 & 10.00 & 11.67 \\
\hline BB-H3 & 5.00 & 10.42 & 13.33 \\
\hline AB-H3 & 5.00 & 9.58 & 11.67 \\
\hline A-H5 & \multicolumn{3}{|c|}{$3.53^{*}$} \\
\hline B-H5 & \multicolumn{3}{|c|}{$5.88^{*}$} \\
\hline AA-H5 & 5.42 & 10.00 & 10.83 \\
\hline BB-H5 & 5.83 & 9.17 & $9.58 ?$ \\
\hline AB-H5 & 5.42 & 9.17 & 9.58 \\
\hline A-H7 & \multicolumn{3}{|c|}{$4.71^{*}$} \\
\hline B-H7 & \multicolumn{3}{|c|}{$15.29^{*}$} \\
\hline AA-H7 & 5.00 & 10.83 & 31.25 \\
\hline BB-H7 & 5.83 & 8.33 & 70.83 \\
\hline AB-H7 & 6.67 & 9.17 & 30.00 \\
\hline A-R3 & \multicolumn{3}{|c|}{$3.24^{*}$} \\
\hline B-R3 & \multicolumn{3}{|c|}{$3.53^{*}$} \\
\hline AA-R3 & 6.67 & 10.83 & 13.33 \\
\hline BB-R3 & 6.25 & 11.67 & 20.83 \\
\hline AB-R3 & 6.67 & 11.25 & 12.50 \\
\hline A-K3 & \multicolumn{3}{|c|}{$4.41^{*}$} \\
\hline B-K3 & \multicolumn{3}{|c|}{$7.98^{*}$} \\
\hline AA-K3 & 6.67 & 7.50 & 10.42 \\
\hline BB-K3 & 9.58 & 9.58 & 30.00 \\
\hline AB-K3 & 8.33 & 8.33 & 10.00 \\
\hline
\end{tabular}

Notes: the impact strength (W) was determined at RT using $2.9 \mathrm{~m} / \mathrm{s}$ impact speed. The coding of the materials is referred in the text. Data with * are measured on standardised, notched specimens

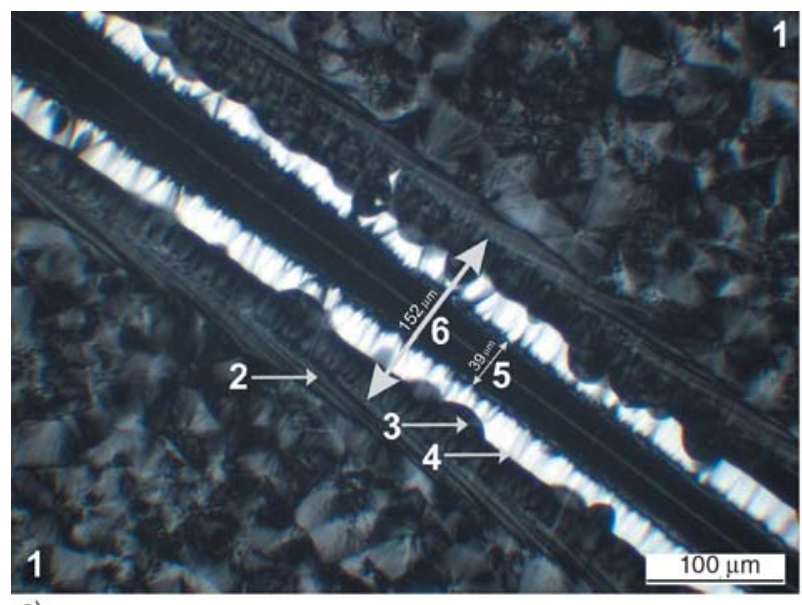

a)

Figure 4. a) PLM micrograph on the morphology of the AA-H7 weld produced at a welding pressure of $p=0.5 \mathrm{MPa}$ (middle part of the weld). Designations: 1 - parent plaque, 2 - layer with deformed spherulites, 3 - spherulitic layer, 4 - beta-cylindrite due to shear induced nucleation, 5 - melt flow channel, 6 - overall thickness of the weld seam. b) PLM micrograph taken with lambda plate failure in the welded $\mathrm{AB}$ pairs occurred always in the alpha part close to the weld joint. The above test results confirm that joints of very high toughness can be produced when plaques of beta-nucleated iPPs of low MFI are welded together. However, this claim holds only for BB pairs, i.e. when both plaques are beta-nucleated.

\subsection{Supermolecular structure of the welding joint}

The supermolecular structure of the weld joint is controlled by the actual thermal, mechanical and flow conditions, which all affect the recrystallisation of the molten layer during welding. The above conditions strongly change with the geometrical place. The complex supermolecular structure obtained at low pressure welding for the pairs AA$\mathrm{H} 7, \mathrm{BB}-\mathrm{H} 7, \mathrm{AB}-\mathrm{H} 7$ and $\mathrm{AA}-\mathrm{H} 5$, respectively, are shown in Figures 4-8. The related PLM micrographs are taken from microtomed sections cut transverse to both the plaque plane (i.e. along the cross section) and the welding joint. One can see that the non-nucleated plaques contain large alphaspherulites, in which few negative beta-spherulites are sporadically embedded. The average size is about 50-60 micrometer (cf. Figure 4). The size of the beta-spherulites of beta-nucleated plaques is markedly lower and their size is more uniform than in the alpha plaques (Figure 6).

The shape of the joints welded at low pressure is similar for the different PP combinations: the joint

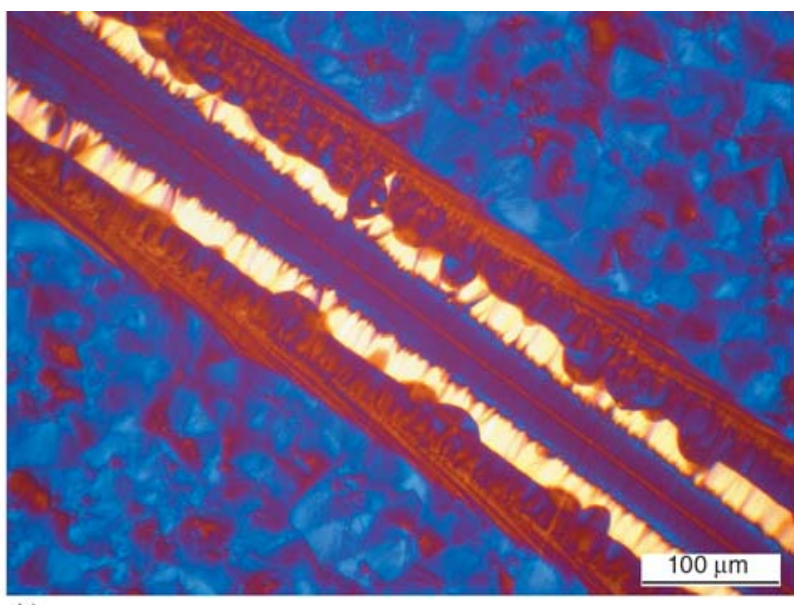

b) 


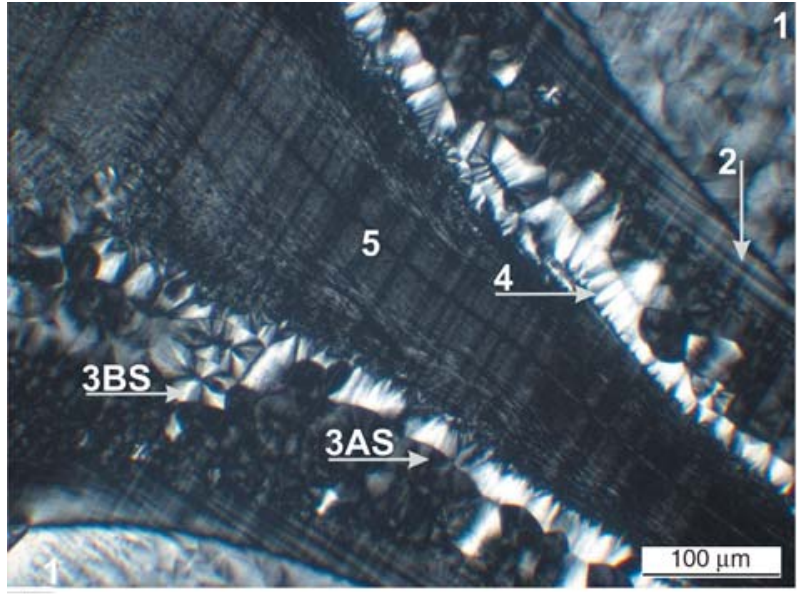

a)

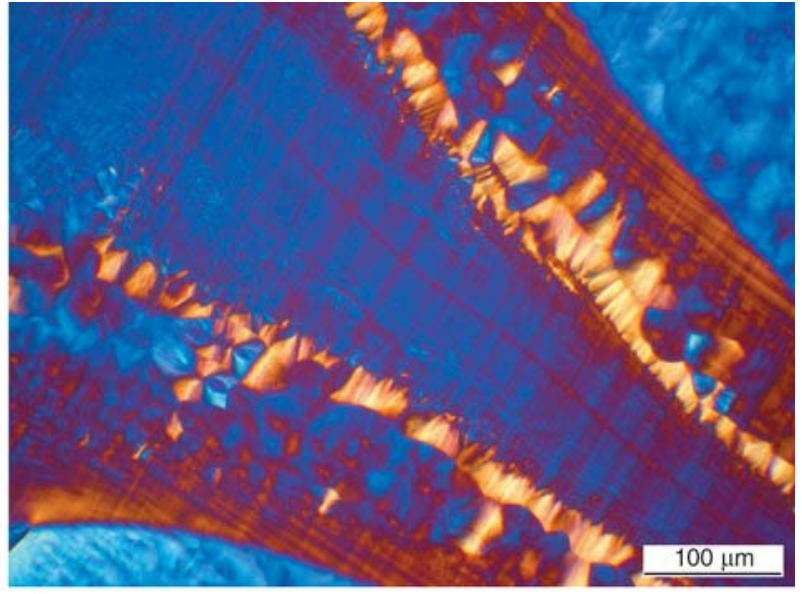

b)

Figure 5. a) PLM micrograph on the morphology of the AA-H7 weld produced at a welding pressure of $p=0.5 \mathrm{MPa}$ (outer part, close to the flash). Designations: 1 - parent plaque, 2 - layer with deformed spherulites, $3 \mathrm{AS}$ and 3BS - individual alpha and beta-spherulites in the spherulitic layer, 4 - beta-cylindrite due to shear induced nucleation, 5 - melt flow channel. b) PLM micrograph taken with lambda plate

has the same thickness in the middle section and broadens somewhat only towards the edges of the plaques (Figure 5). The formation of the multilayer structure in non-nucleated iPP welds was explained in our earlier works $[4,16]$ by the onset of a molten layer consisting of two zones with different flowability. In the middle section of the joint a so-called flow channel developed being flanked by plastic zones from both sides. In the plastic zone the melt viscosity is high owing to the locally low temperature. So, the related zone has some restricted flow especially under low welding pressures. Crystallisation in the plastic zones occurs under quasi-quiescent melt conditions. Accordingly, microcrystalline and/or spherulitic structures appear depending on the actual thermal conditions. It is worth of noting that in the spherulitic layers the size of the spherulites is smaller than in the parent plaques. This testifies that the spherulites were recrystallised from the melt. In the flow channel flow-induced cylindirtic crystallisation took place. Cylindrites are induced by row nuclei and oriented along the flow direction. Owing to the very high density of nuclei, the resulting supermolecular structure can hardly be resolved in optical level. The spherulites of the parent plaques in the vicinity of the molten layer undergo partial melting. The partially molten spherulites deform upon the acting pessure and orient themselves towards the flash. As a consequence, at the boundary of the parent plaque and the weld joint, a layer composed of deformed spherulites appears. The extent of spherulite defor- mation and the thickness of the related layer increase towards the edges of the welded plaques (cf. Figures 4 and 5).

Apart of the above supermulecular features, a further peculiarity can be observed in the welds of the specimens AA-H7 (Figure 5) and AA-H5 (Figure 8). It both outer flanks of the flow channel a highly birefringent, negative-type beta layers can be recognised. These layers, rich in beta modification of iPP, are generated by the shear stresses developed between the flow and plactic zones. The influence of the related 'shearing' on the resulting supermolecular structures was the topic of our former works (e.g. [17]). It has to be emphasised that the beta-rich layers are far more prominent in the AA-H7 (cf. Figure 5) than in the AA-H5 specimens (cf. Figure 8). Moreover, no such layer could be resolved in the AA-H3 weld pairs at all. This is a clear indication that with decreasing melt viscosity (from $\mathrm{H} 7$ towards $\mathrm{H} 3$ ) of the iPP the evolving shear stress in the boundary layer between the flow and plastic zones decreases and thus no shear-induced beta nucleation has been triggered.

The formation of this beta-rich layer is hampered in beta-nuclated iPP owing to the beta-nucleator present (cf. Figure 6). Note that in presence of the beta nucleator the spherulitic crystallisation occurs at higher temperature and/or at higher rate than the cylindritic one.

It is clearly perceptible in Figure 7 that the nonnucleated and beta-nucleated melts in the welded AB pairs do not interpenetrate. So, the supermolec- 


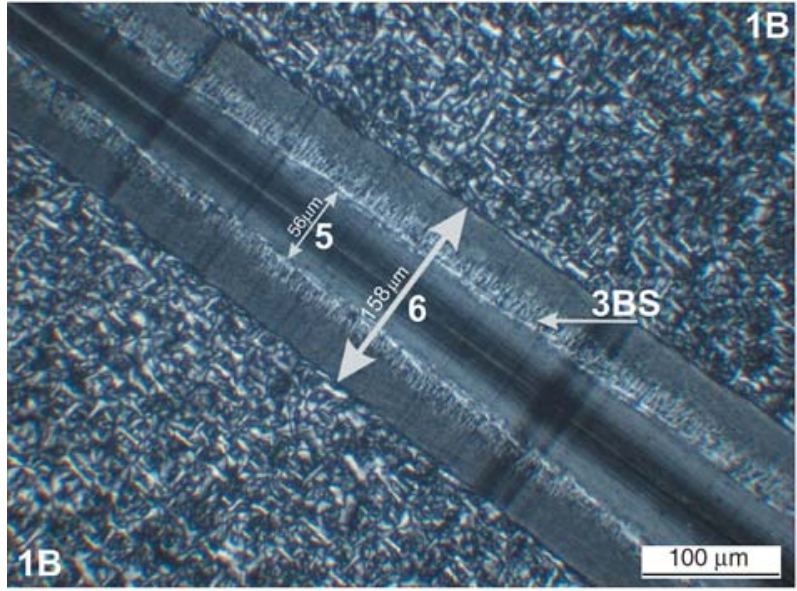

a)

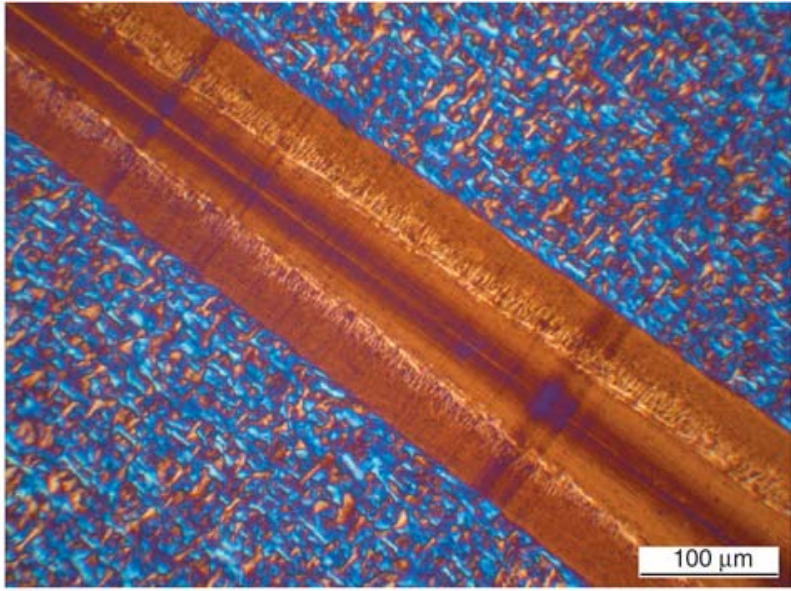

b)

Figure 6. a) PLM micrograph on the morphology of the BB-H7 weld produced at a welding pressure of $p=0.5 \mathrm{MPa}$. Designations: 1B - parent plaque, 3BS - beta-spherulitic layer, 5 - melt flow channel, 6 - overall thickness of the weld seam. b) PLM micrograph taken with lambda plate

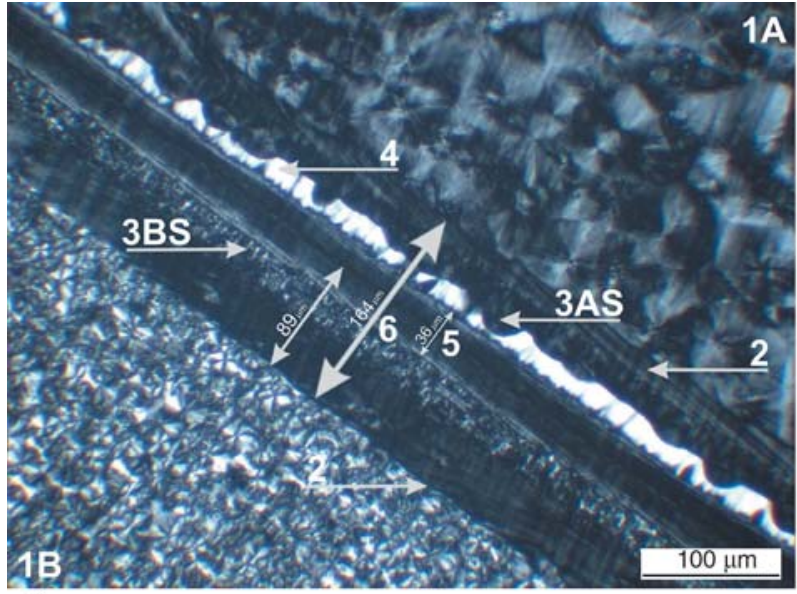

a)

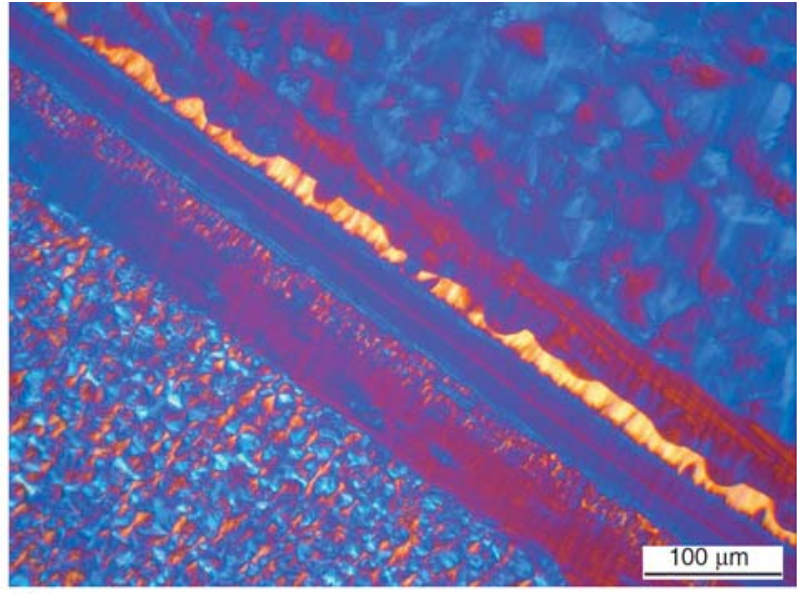

b)

Figure 7. a) PLM micrograph on the morphology of the AB-H7 weld produced at a welding pressure of $p=0.5 \mathrm{MPa}$. Designations: $1 \mathrm{~A}$ and $1 \mathrm{~B}$ - non-nucleated and beta-nucleated parent plaques, 2 - layer with deformed spherulites, 3AS and 3BS - beta-spherulitites, 4 - beta-cylindrite due to shear induced nucleation, 5 - melt flow channel, 6 - overall thickness of the weld seam. b) PLM micrograph taken with lambda plate

ular structure located between the contact plane and the parent plaques on the $\mathrm{A}$ and $\mathrm{B}$ sides is identical what can be found in AA and BB pairs. The above described morphlogical features are well demonsrtrated in the PLM micrographs in Figures 4-8. The interpretation of the related morphologies is supported by the exhaustive legends of the corresponding figures. The rules of the formation of multilayered weld appearance will be the topics of a companion contribution.

The morphology of the joint is far less complex when produced at high welding pressures $(p=2$ and $8 \mathrm{MPa}$ ). Figure 9 shows that the weld seam is smaller compared to the joint produced at low pressure (cf. Figures 4-8). The supermolecular struc- ture, produced at high welding pressure, cannot be resolved optically - during this joint formation obviously the melt flow dominated. This induced an oriented cylindritic structure in the whole joint. The related joints show the same characteristics as described by us earlier using non-nucleated iPPs for welding [3-9]. It is noteworthy that the joint accommodates a delta shape at the edges of the welded plaques. Moreover, the weld thickness in the flash is markedly larger compared to that of the middle section. The single layer morphology due to high pressure welding contains highly oriented molecules and related supermolecular structures, the orientation of which is transverse to the static mechanical loading and parallel to the impact 


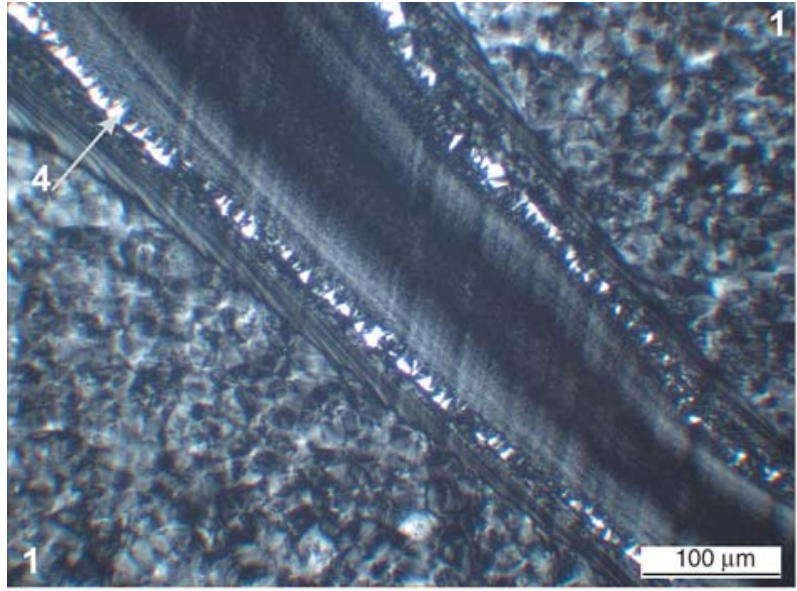

a)

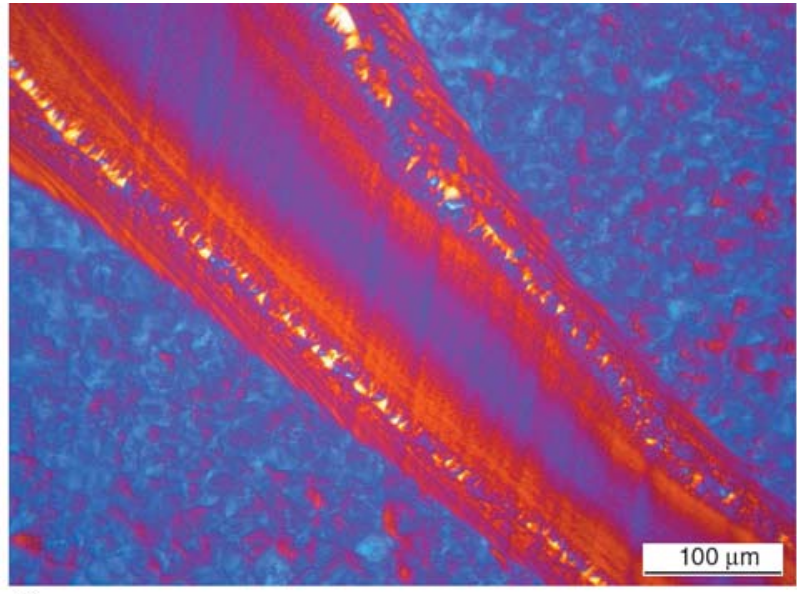

b)

Figure 8. a) Shear induced beta-cylindritic layer in weld seam of AA-H5 plaques produced at a welding pressure of $p=0.5 \mathrm{MPa}$. b) PLM micrograph taken with lambda plate

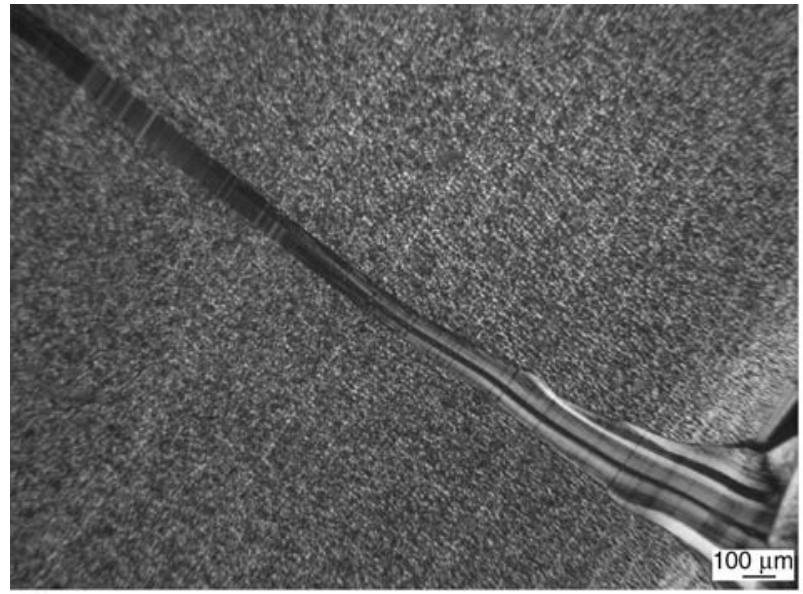

a)

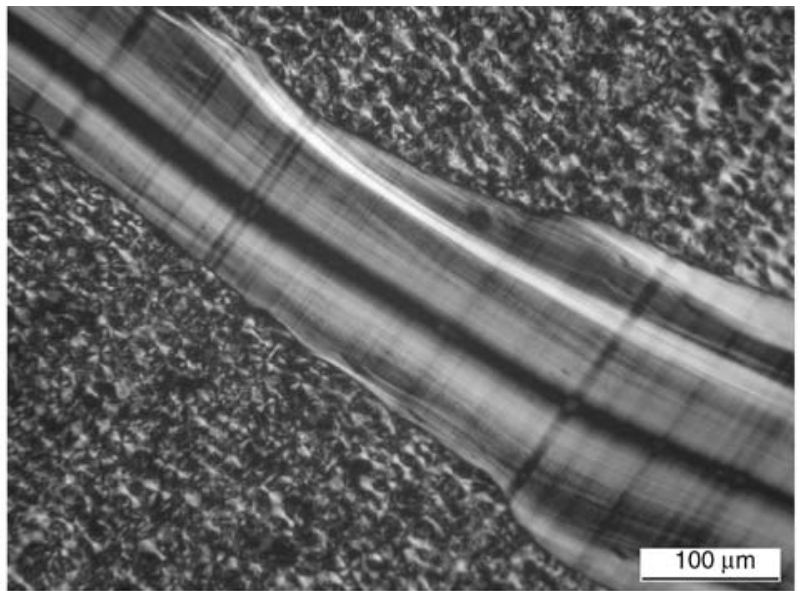

b)

Figure 9. a) PLM micrographs showing the supermolecular structures in BB-H5 weld produced at a high welding pressure $(p=8 \mathrm{MPa})$. b) A part of the weld at higher magnification

direction. This is disadvantageous for both cases, which is well reflected by the related results. One can thus speculate that this layer has some stress concentration effect. By contrast, the multiple layer structure of the welds, generated by low pressure welding, has some gradient structure in mechanical sense. The stress imposed can be more efficiently spread, transferred to a large area, due to which the load bearing capacity of the welds is strongly improved (cf. data in Tables 2 and 3).

\section{Conclusions}

Based on this work addressing the property-structure relationships in vibration welded polypropylene plaques without and with beta nucleation, the following conclusions can be drawn:
- The mechanical and impact strength of the joints can be markedly improved using beta-nucleated PPs. It was also found that the lower the melt flow index of the beta-iPP, the higher the property improvement under static and dynamic conditions. This beneficial effect can be, however, only triggered when both welded parts are betanucleated versions and relatively low welding pressures are applied.

- The outstanding weld strengths of parts joined at low welding pressure are connected with their complex multilayer structure. Its formation is due to the development of two molten zones of highly different flowability. In the vicinity of the initial contact surface a flow channel develops, which is flanked from both sides by plastic zones. In the flow channel flow-induced crystallisation occurs resulting in an oriented cylin- 
dritic structure. In the plastic zone the crystallisation takes place in a quasi quiescent melt yielding spherulitic and/or microcrystalline structures. This multilayer structure ensures an efficient stress transfer via its complex morphology so that the corresponding weld shows excellent static and dynamic mechanical properties.

- High welding pressure results in a single layer weld with strongly aligned molecules and supermolecular structures. As their orientation is disadvantageous in respect to the static and dynamic loadings and the oriented layer acts as stress concentrator, the welds exhibit low performance.

\section{Acknowledgements}

The authors thank the Volkswagen Foundation for the financial support of this project. Thanks are also to M. Giese, J. Vetter and I. Mudra for their involvement in the experimental works.

\section{References}

[1] Andrew W.: Handbook of plastics joining: A practical guide. Plastic Design Library, Norwich (1997).

[2] Potente H., Michel P., Ruthmann B.: Eine Analyse des Vibrationsschweissens. Kunststoffe, 77, 711-716 (1987).

[3] Schlarb A. K., Ehrenstein G. W.: Vibrationsschweißen - Ein Serienschweißverfahren aus werkstofftechnischer Sicht. Kunststoffe, 78, 541-545 (1988).

[4] Schlarb A. K., Ehrenstein G. W., Varga J.: Vibration welding of polypropylene (in Hungarian). Plastics and Rubber, 25, 339-347 (1988).

[5] Schlarb A. K.: Zum Vibrationsschweißen von Polymerwerkstoffen. PhD Dissertation, Universität Kassel (1989).

[6] Schlarb A. K., Ehrenstein G. W.: The impact strength of butt welded vibration welds related to microstructure and welding history. Polymer Engineering and Science 29, 1677-1682 (1989).
[7] Giese M., Ehrenstein G. W.: Studies of the deformation and failure behavior of vibration welded polypropylene welds. in 'Antec 92, Conference Proceedings, Detroit, USA' 349-352. (1992).

[8] Giese M.: Fertigungs- und werkstofftechnische Betrachtungen zum Vibrationsschweißen von Polymerwerkstoffen. PhD Dissertation, Universität ErlangenNürnberg (1995).

[9] Vetter J., Ehrenstein G. W.: Online-Qualitäts-Erkennung beim Vibrationsschweissen: Neuronale Netzwerke klassifizieren Schweissnahtfestigkeit. Kunststoffe, 88, 986-989 (1998).

[10] Varga J.: $\beta$-Modification of isotactic polypropylene: preparation, structure, processing, properties, and application. Journal of Macromolecular Science, Part B: Physics, 41, 1121-1171 (2002).

[11] Varga J., Mudra I., Ehrenstein G. W.: Morphology and properties of $\beta$-nucleated injection molded isotactic polypropylene. in 'Antec 98, Conference Proceedings, Atlanta, USA' Vol. III., 3492-3496 (1998).

[12] Karger-Kocsis J., Varga J., Ehrenstein G. W.: Comparison of the fracture and failure behavior of injection-molded $\alpha$ - and $\beta$-polypropylene in high-speed three-point bending tests. Journal of Applied Polymer Science, 64, 2057-2066 (1997).

[13] Varga J., Mudra I., Ehrenstein G. W.: Highly active thermally stable $\beta$-nucleating agents for isotactic polypropylene. Journal of Applied Polymer Science, 74, 2357-2368 (1999).

[14] Karger-Kocsis J., Friedrich K.: Effect of skin-core morphology on fatigue crack propagation in injectionmoulded polypropylene homopolymer. International Journal of Fatigue, 11, 161-168 (1989).

[15] Turner-Jones A., Aizlewood J. M., Beckett D. R.: Crystalline forms of isotactic polypropylene. Macromolecular Chemistry, 75, 134-154 (1964).

[16] Varga J.: Supermolecular structure of isotactic polypropylene. Journal of Materials Science, 27, $2557-$ 2579 (1992).

[17] Varga J., Karger-Kocsis J.: Rules of supermolecular structure formation in sheared isotactic polypropylene melts. Journal of Polymer Science, Part B: Polymer Physics, 34, 657-670 (1996). 